\title{
Repression domain of the yeast global repressor Tup1 interacts directly with histones $\mathrm{H} 3$ and $\mathrm{H} 4$
}

\author{
Diane G. Edmondson, ${ }^{1}$ M. Mitchell Smith, ${ }^{2}$ and Sharon Y. Roth ${ }^{1,3}$ \\ ${ }^{1}$ Department of Biochemistry and Molecular Biology, University of Texas M.D. Anderson Cancer Center (UTMDACC), \\ Houston, Texas 77030 USA; $^{2}$ Department of Microbiology, University of Virginia School of Medicine, Charlottesville, \\ Virginia 22908 USA
}

Repression of yeast $a$ cell-specific genes by the global repressor Ssn6/Tup1 has been linked to a specific organization of chromatin. We report here that Tup1 directly interacts with the amino-terminal tails of histones $\mathrm{H} 3$ and $\mathrm{H} 4$, providing a molecular basis for this connection. This interaction appears to be required for Tup1 function because amino-terminal mutations in $\mathrm{H} 3$ and $\mathrm{H} 4$ that weaken interactions with Tupl cause derepression of both $a$ cell-specific and DNA damage-inducible genes. Moreover, the Tup1 histone-binding domain coincides with the previously defined Tup1 repression domain. Tup1/histone interactions are negatively influenced by high levels of histone acetylation, suggesting a mechanism whereby the organization of chromatin may be modulated in response to changing environmental signals.

[Key Words: Ssn6/Tupl; chromatin; repression; histones; transcription]

Received February 6, 1996; revised version accepted April 10, 1996.

The yeast Ssn6/Tupl repressor complex provides a unique paradigm for repression of transcription. These complexes repress diverse genes that maintain cell type or respond to changing physiological conditions. For example, Ssn6/Tupl is required to mediate repression of cell type-specific genes by the $\alpha 2$ repressor (Keleher et al. 1992) and is also required for repression of glucose-repressible genes such as SUC2 (Carlson et al. 1984; Trumbly 1986; Williams et al. 1991), DNA damage-inducible genes such as RNR3 (Zhou and Elledge 1992), and genes regulated by oxygen such as $A N B 1$ (Zitomer and Lowry 1992). Neither Ssn6 nor Tupl binds directly to DNA, and these factors appear to be targeted to particular promoters through interactions with specific DNA-binding proteins such as $\alpha 2$ (Komachi et al 1994; Smith et al. 1995; Treitel and Carlson 1995; Tzamarias and Struhl 1995). If directed to specific promoters via fusion to a heterologous DNA-binding domain, either Ssn6 or Tupl can mediate repression (Keleher et al. 1992; Tzamarias and Struhl 1994). Although repression by Ssn6 requires Tupl (Keleher et al. 1992), Tupl can repress transcription in the absence of Ssn6 (Tzamarias and Struhl 1994). Tup1, then, may serve as the active repressor subunit of the complex, whereas Ssn6 may mediate or stabilize interactions between Tupl and various targeting proteins.

Ssn6 (Cyc8) is a large $(107-\mathrm{kD})$ phosphoprotein that contains 10 tandem copies of a tetratricopeptide repeat (TPR) (Schultz and Carlson 1987; Schultz et al. 1990).

\footnotetext{
${ }^{3}$ Corresponding author.
}

This domain appears to mediate protein-protein interactions. The first three TPR motifs are required for interaction with Tupl, whereas most or all of the TPRs are capable of interacting with $\alpha 2$ (Smith et al. 1995; Tzamarias and Struhl 1995). Different repeats within the TPR domain are required for repression of different sets of genes. Only the first 3 repeats are required for repression of a cell-specific genes, for example, but all 10 repeats are required for repression of DNA damage-inducible genes (Tzamarias and Struhl 1995). The ability to interact with multiple proteins is consistent with the proposal that Ssn6 acts as an adapter between Tupl and various DNA-binding proteins.

Several functional domains have been identified in Tupl. The carboxy-terminal half of Tupl contains eight repeats of a 43-amino-acid sequence rich in aspartate and tryptophan (WD-40 repeats) (Fong et al. 1986; Williams and Trumbly 1990; Mukai et al. 1991). This domain also serves as a protein interaction domain, and WD repeats 1 and 2 directly interact with $\alpha 2$ (Komachi et al. 1994). The amino-terminal 72 amino acids of Tupl are required for interaction with Ssn6 and for multimerization of Tupl (Tzamarias and Struhl 1995). In addition, two alaninerich repression domains have been identified in Tupl using Tupl-lexA fusion proteins (Tzamarias and Struhl 1994).

Despite the detailed characterization of these two proteins, the mechanisms by which Ssn6/Tupl confer repression are unknown. Given the involvement of Ssn6/ Tupl in the repression of several independently regu- 
lated genes, this complex is likely to interact with some moiety common to multiple promoters. Possible targets include basal transcription factors or components of chromatin. Evidence exists to support both of these possibilities. Ssn6/Tup1 repression of an a cell-specific reporter can be reconstituted in vitro, in the absence of chromatin, on addition of recombinant $\alpha 2$ protein and nuclear extracts from cells overexpressing Ssn6 and Tupl (Herschbach et al. 1994), indicating that Tupl may act on a component of the basal transcription machinery. However, the modest repression (2- to 4-fold) observed in these experiments is much lower than that observed in vivo (>200-fold), indicating that some factors may be limiting or missing in these nuclear extracts.

Other experiments suggest that Ssn6/Tupl repression is mediated in vivo through organization of chromatin. Repression of a cell-specific genes in haploid $\alpha$ and diploid a/ $\alpha$ cells is linked to a precise and stable positioning of nucleosomes adjacent to the $\alpha 2$ operator (Roth et al. 1990; Shimizu et al. 1991). In a cells, where $\alpha 2$ is not expressed, Ssn6/Tupl is not targeted to a cell-specific promoters and nucleosomes are randomly positioned at these loci. Mutation of either SSN6 or TUP1 results in derepression of the a cell-specific genes and perturbation of the placement and stability of nucleosomes adjacent to the $\alpha 2$ operator (Cooper et al. 1994). Stable nucleosome positioning and complete repression require not only $\alpha 2$, Ssn6, and Tup1, but also the amino-terminal "tail" of histone H4 (Roth et al. 1992). These factors appear to cooperate to create a repressive region of chromatin. Organized chromatin structures are also observed for other genes regulated by Ssn6/Tupl (Hirschorn et al. 1992; Matallana et al. 1992).

If Ssn6/Tupl functions by modulating chromatin structure, these factors might directly interact with nucleosomal proteins. The interaction of the silent information regulators, Sir3 and Sir4, with histones provides a precedent for such interactions (Hecht et al. 1995). We report here that a previously defined repression domain in Tupl interacts specifically with the amino termini of histones $\mathrm{H} 3$ and $\mathrm{H} 4$ and that these interactions are influenced by the acetylation state of the histones. Moreover, mutations in the amino-terminal region of $\mathrm{H} 3$ or $\mathrm{H} 4$ that abolish or weaken interactions with Tupl compromise Tupl-mediated repression. Our data strongly suggest that Ssn6/Tupl complexes may directly modulate chromatin structure to repress gene expression.

\section{Results}

\section{Tup1 interacts with histones $\mathrm{H} 3$ and $\mathrm{H} 4$}

Current models propose that Ssn6/Tupl complexes are targeted to specific promoters through interactions with DNA-binding proteins, such as $\alpha 2$, and that once recruited to a promoter, Tupl initiates repression (Keleher et al. 1992; Tzamarias and Struhl 1994, 1995). Given the link we had observed previously between chromatin structure and Tupl-mediated repression of the a cellspecific genes (Shimizu et al. 1991; Roth et al. 1992;
Cooper et al. 1994), we investigated whether Tup1 might directly interact with histones.

We first assayed these interactions by a FAR Western blot analysis. Acid-soluble yeast nuclear proteins enriched in histones were separated by SDS-PAGE, electroblotted, and probed with in vitro-translated, ${ }^{35} \mathrm{~S}$-labeled Tup1 (Tup1; Fig. 1A), or an unprogrammed translation reaction ("No RNA;" Fig. 1A). The labeled Tupl bound to three proteins, but no signal was obtained with the unprogrammed translate. The bands interacting with

A
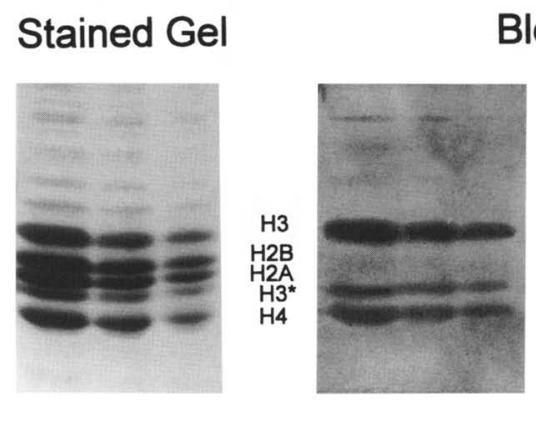

Tup1

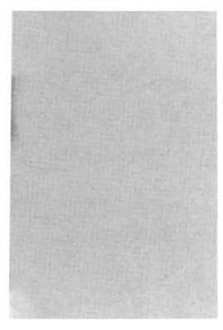

'No RNA'

B

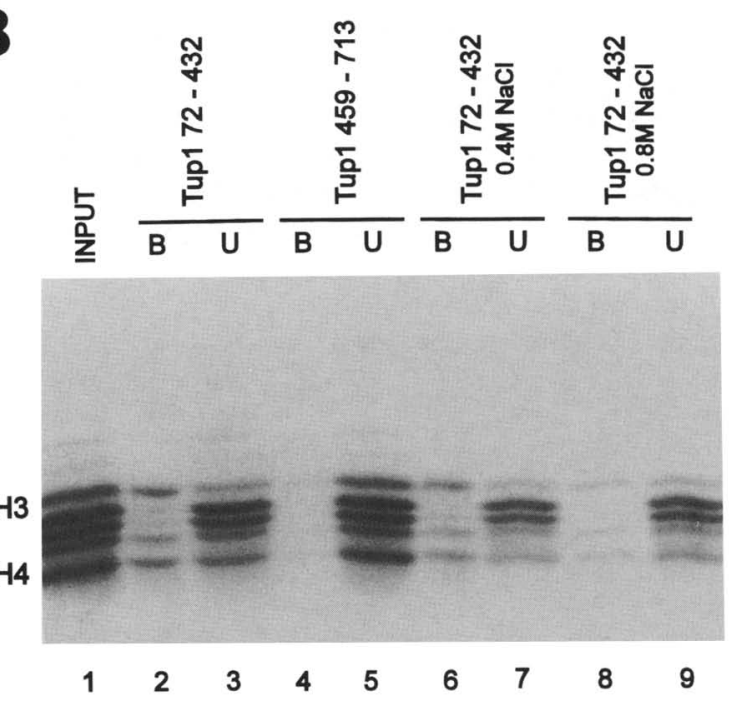

Figure 1. Tupl interacts with histones $\mathrm{H} 3$ and $\mathrm{H} 4$. (A) FAR Western blot analysis. Samples of yeast histones were separated by SDS-PAGE, electroblotted to PVDF membrane, and probed with an ${ }^{35}$ S-labeled Tupl probe (Tupl) or with an unprogrammed reticulocyte lysate "probe" ("No RNA"). Parallel lanes were stained with Coomassie Brilliant blue R (stained gel). The three lanes contain decreasing loads of histone. $(B)$ Binding of $\mathrm{H} 3$ and $\mathrm{H} 4$ to Tup1-Sepharose. Cyanogen bromide-activated Sepharose beads were coupled to purified recombinant Tup $1_{172-432)}$ or Tupl $1_{(459-713)}$ proteins. Yeast histone samples were added to the beads and allowed to bind. Bound $(B$, lanes $2,4,6,8)$ and unbound $(U$, lanes $3,5,7,9)$ fractions were then analyzed by SDS-PAGE and Coomassie blue staining. An aliquot of the input histone protein sample is shown in lane 1. 
Tupl were identified by mobility and confirmed by Western blot analysis (data not shown) as histones $\mathrm{H} 3$, $\mathrm{H} 4$, and a spontaneous breakdown product of histone $\mathrm{H} 3$ (H3* ; Fig. 1A; sometimes called P1 *; Bohm et al. 1981; Bortvin and Winston 1996) that is commonly seen in histone preparations from a number of organisms. Varying amounts of this autolysed $\mathrm{H} 3$ were observed in individual yeast histone preparations (data not shown, but see panels in Fig. 4A, below, for examples). Importantly, Tupl did not bind to histones $\mathrm{H} 2 \mathrm{~A}$ or $\mathrm{H} 2 \mathrm{~B}$, indicating that binding to $\mathrm{H} 3$ and $\mathrm{H} 4$ is unlikely to be mediated by nonspecific charge interactions, because $\mathrm{H} 2 \mathrm{~A}$ and $\mathrm{H} 2 \mathrm{~B}$ are also highly positively charged. Also, no interactions were observed between Tupl and other small, highly basic molecules such as lysozyme (data not shown).

To confirm interaction of Tup 1 with histones $\mathrm{H} 3$ and $\mathrm{H} 4$, we investigated the ability of free histones to bind to Tupl immobilized on Sepharose beads. We were unable to express full-length Tupl in bacteria but were able to express two partial Tupl products: Tupl/amino acids 72-432 and Tupl/amino acids 459-713. Purified proteins were coupled to Sepharose beads and incubated with yeast nuclear proteins (as above), and then the bound and unbound fractions were analyzed by SDSPAGE. Histones $\mathrm{H} 3$ and $\mathrm{H} 4$ bound to the Tupl $\mathrm{l}_{(72-432)^{-}}$ coupled beads (Fig. 1B, lane 2), whereas histones H2A and $\mathrm{H} 2 \mathrm{~B}$ remained in the unbound fraction (Fig. $1 \mathrm{~B}$, lane 3). None of the core histones bound to the Tup $1_{\left(459-\left.713\right|^{-}\right.}$ coupled beads (Fig. 1B, lane 4). Interestingly, the Tupl $1_{(72-432)}$ protein (which binds histones $\mathrm{H} 3$ and $\mathrm{H} 4$ ) contains the putative repression domain of Tupl, whereas Tupl $1_{(459-713)}$ contains the WD repeats of Tupl (see Fig. 4, below).

We then examined the stability of the Tupl-histone complex under conditions of high ionic strength. Histones bound to Tup $1_{(72-432)^{-}}$coupled beads were washed first with binding buffer and then with buffer containing $0.4 \mathrm{M}$ or $0.8 \mathrm{M} \mathrm{NaCl}$. Even in the presence of $0.8 \mathrm{M} \mathrm{NaCl}$, significant amounts of histones $\mathrm{H} 3$ and $\mathrm{H} 4$ remained bound to the Tupl $1_{(72-432)}$-coupled beads (Fig. 1B, lane 8). Histones were not precipitated nonspecifically by high salt because $\mathrm{H} 3$ and $\mathrm{H} 4$ are not found in the bound fraction when Tupl $1_{(459-713)}$-coupled beads are mixed with histones in high salt (data not shown). The persistence of Tupl/histone interaction under conditions of high salt suggests that, once formed, the interaction is fairly insensitive to ionic interactions.

\section{Tup1 interacts with underacetylated forms of histones $\mathrm{H} 3$ and $\mathrm{H} 4$}

Interestingly, only a fraction of the total $\mathrm{H} 3$ and $\mathrm{H} 4$

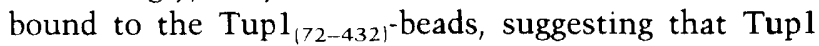
may only bind to specifically modified isoforms of these histones. Acetylation is a common modification of histones and has been correlated with transcriptional regulation. In yeast, genes that are silenced are associated with hypoacetylated forms of $\mathrm{H} 4$ (Braunstein et al. 1993), and a similar association has been observed in both Drosophila and mammals (Turner et al. 1990, 1992; Jeppesen and Turner 1993; Bone et al. 1994; for review, see Turner 1991). To investigate whether interactions between Tupl and $\mathrm{H} 3$ or $\mathrm{H} 4$ might be influenced by levels of histone acetylation, we performed a FAR Western blot analysis on yeast histone isoforms resolved by acid-urea electrophoresis, again using in vitro-translated Tupl as probe.

Five isoforms of $\mathrm{H} 4$ are distinguished by acid-urea electrophoresis (Fig. 2A), and these bands represent different levels of $\mathrm{H} 4$ acetylation (Allis et al. 1980). The identity of these bands was confirmed using an antibody that recognizes multiply acetylated forms of $\mathrm{H} 4$ (Lin et al. 1989), as well as acetylated H2A in yeast (Fig. 2C). Multiple isoforms of $\mathrm{H} 3$ are also apparent in the stained acid-urea gel, and at least three acetylated isoforms of

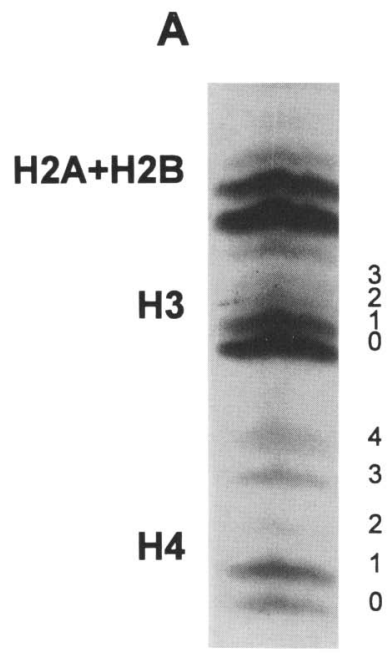

B

Stained gel

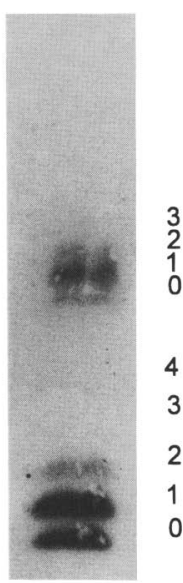

FAR Western
C

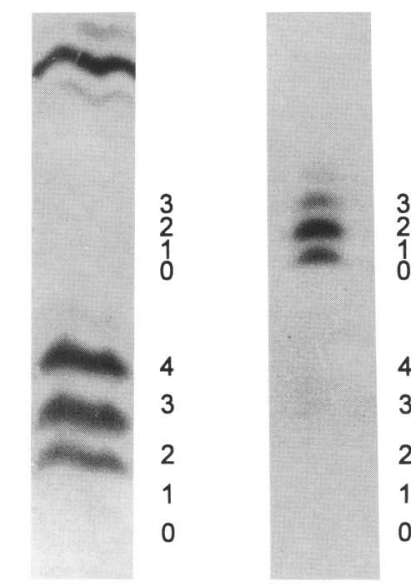

anti-Ac H4/H2A
Anti-Ac $\mathrm{H3}$
Figure 2. Analysis of Tupl binding to acetylated isoforms of $\mathrm{H} 3$ and $\mathrm{H} 4$. Yeast histones were resolved by acid-urea gel electrophoresis. The positions of differentially acetylated isoforms are indicated by numbers to the right of each lane $0=$ unacetylated, $1=$ monoacetylated, $2=$ diacetylated, $3=$ triacetylated, $4=$ tetra-acetylated). (A) Coomassie blue stained gel. (B) FAR Western blot using radiolabeled Tup1 probe. (C) Western blot using anti-acetylated $\mathrm{H} 4$ / H2A antibodies. $(D)$ Western blot using anti-acetylated $\mathrm{H} 3$ antibodies. Note the $\mathrm{ab}$ sence of Tupl binding to tri- and tetra-acetylated forms of $\mathrm{H} 3$ and $\mathrm{H} 4$. 
$\mathrm{H} 3$ are detected in this histone preparation (Fig. 2D) by an antibody directed against acetylated $\mathrm{H} 3$.

Tupl interacts solely with the unacetylated, monoacetylated, and diacetylated forms of histone $\mathrm{H} 4$ and preferentially binds monoacetylated H3 (Fig. 2B). No Tupl binding was observed to the more highly /tri- and tetra-| acetylated forms of either histone. The binding of Tupl to underacetylated histones is consistent with the long-standing correlation between histone deacetylation and transcriptional repression (Turner 1991) and suggests a mechanism whereby interactions between Tupl and the histones might be modulated easily.

\section{The amino termini of histones $\mathrm{H} 3$ and $\mathrm{H} 4$ are required} for interaction with Tup1

Acetylation of $\mathrm{H} 3$ and $\mathrm{H} 4$ occurs at highly conserved lysine residues in the amino-terminal regions of these histones (Turner 1991). Because binding of Tupl to these histones is influenced by acetylation, these interactions are likely to involve these amino-terminal regions. Moreover, we have shown previously that deletions or point mutations in the amino-terminal region of $\mathrm{H} 4$ affect both nucleosome positioning and repression of the $\mathbf{a}$ cell-specific genes (Roth et al. 1992), further indicating that this histone domain is important to Tupl-mediated repression.

To determine whether the amino-terminal region of $\mathrm{H} 4$ is required for a direct interaction with Tupl, we prepared histones from the strains of yeast used in the aforementioned regulatory studies. These isogenic strains contain either wild-type $\mathrm{H} 4$ (Fig. 3A, lanes 2,3), a deletion of amino acids 4-19 [del(4-19); lane 1], or a deletion of amino acids 4-14 [del(4-14); lane 4] (Kayne et al. 1988). The FAR Western blot analysis revealed that whereas Tupl bound quite well to $\mathrm{H} 3$ in all three histone preparations, it bound well only to $\mathrm{H} 4$ isolated from wild-type cells (Fig. 3A, lanes $2^{\prime}, 3^{\prime}$ ). Deletion of amino acids 4-14 weakened Tupl binding (lane $4^{\prime}$ ) by $50 \%-$ $60 \%$ (relative to wild-type $\mathrm{H} 4$ ) as indicated by densitometric scanning of the $\mathrm{H} 4$ signal in the stained gels and corresponding autoradiograms shown in Figure 3 (see Materials and methods section). Importantly, deletion of amino acids 4-19 in $\mathrm{H} 4$ abolished interaction of this his-

A
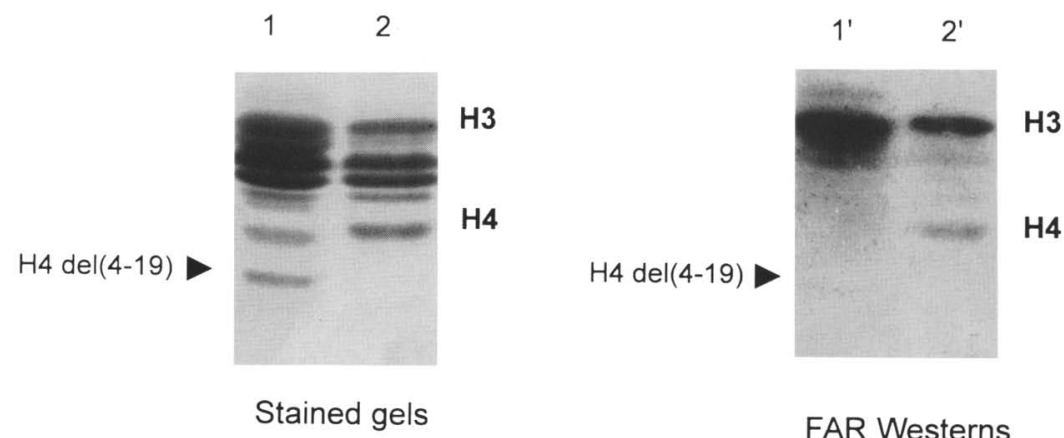

Figure 3. Tupl interacts with the amino termini of histones $\mathrm{H} 3$ and $\mathrm{H} 4$. (A) Histone samples, prepared from isogenic strains carrying wild-type histones (lanes 2,2', $\left.3,3^{\prime}\right)$, deletion of amino acids 4-19 in $\mathrm{H} 4$ (lanes $1,1^{\prime}$ ), deletion of amino acids $4-14$ in $\mathrm{H} 4$ (lanes $4,4^{\prime}$ ), or a point mutation in $\mathrm{H} 4$ converting lysine 16 to glycine (lanes $5,5^{\prime}$ ) were analyzed by Coomassie staining (left) or by FAR Western blot (right) using a Tupl probe. Arrowheads denote positions of the $\mathrm{H} 4 \mathrm{del}(4-19)$ and $\mathrm{H} 4 \operatorname{del}(4-14)$ gene products. $(B)$ Histone samples were prepared from isogenic strains carrying either wild-type $\mathrm{H} 3$ and $\mathrm{H} 4$ (lanes 2,2'), wild-type $\mathrm{H} 3$ and mutated $\mathrm{H} 4$ carrying substitutions of glutamine for the lysines normally present at residues 12 and 16 [H4mut(K12Q,K16Q)] (lanes 3,3'), or H3 deleted for amino acids $1-28$ together with the $\mathrm{H} 4$ (K12Q,Kl6Q) mutation (lanes 1,1'). Parallel lanes were analyzed by Coomassie blue staining (left, lanes 1-3) or by FAR Western blot (right, lanes $\left.1^{\prime}-3^{\prime}\right)$ using a Tupl probe. Position of $\mathrm{H} 3$ del $(1-28)$ is indicated by the arrowhead.

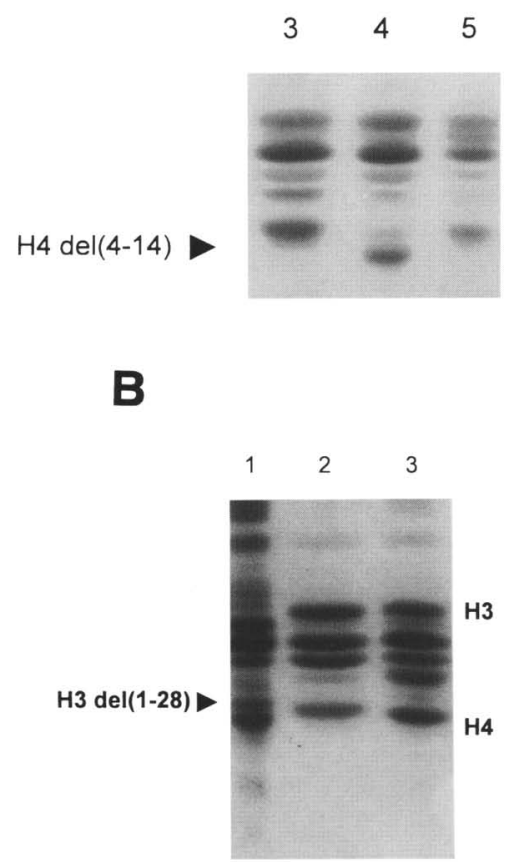

FAR Westerns

H3

H4
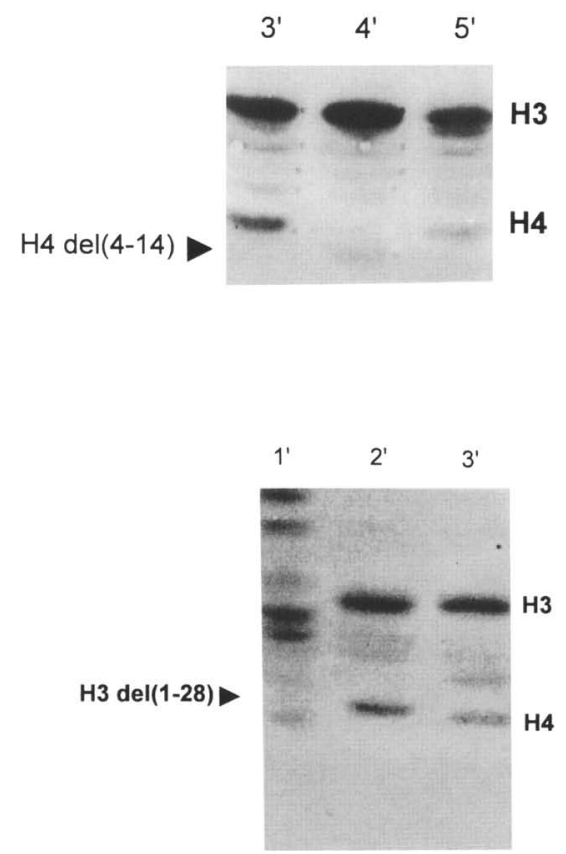
tone with Tupl (Fig. 3A, lane 1'). H4 del(4-19) also failed to bind Tup 1-Sepharose columns, whereas wild-type $\mathrm{H} 3$ in the same histone preparation bound well (data not shown). Together, these results suggest that amino acids 15-19 in H4 are critical for Tup1/H4 interactions, consistent with our previous finding that repression of a cell-specific genes is perturbed in the presence of $\mathrm{H} 4$ del(4-19) (Roth et al. 1992).

We also examined the effects of specific point mutations in $\mathrm{H} 4$ on Tup $1 / \mathrm{H} 4$ interactions. Histones were isolated from isogenic yeast strains bearing either wild-type H4 (Fig. 3A, lane 3) or a substitution of glycine for the lysine residue normally present at position 16 (K16G) (Fig. 3A, lane 5). In a separate experiment, we examined a double point mutation in $\mathrm{H} 4$ that substitutes glutamine for lysines 12 and $16(\mathrm{~K} 12 \mathrm{Q}, \mathrm{K} 16 \mathrm{Q})$ (Megee et al. 1995) (Fig. 3B, lane 3). This double point mutation alters the mobility of $\mathrm{H} 4$ in SDS gels such that it migrates slightly faster than wild-type $\mathrm{H} 4$ (Fig. 3B, cf. lanes 2 and 3). Again, in a Far Western blot analysis, Tupl bound to wild-type $\mathrm{H} 3$ and wild-type $\mathrm{H} 4$ (Fig. $3 \mathrm{~A}$, lane $3^{\prime}$; Fig. 3B, lane $\left.2^{\prime}\right)$, but both $\mathrm{H} 4$ mutations weakened Tupl binding by $50 \%-60 \%$ (Fig. 3A, lane $5^{\prime}$; Fig. 3B, lane $3^{\prime}$ ).

We then investigated whether Tupl interacts with the amino-terminal region of histone $\mathrm{H} 3$. Histones were isolated from a strain containing a deletion of the first 28 amino acids in $\mathrm{H} 3 \mathrm{del}(1-28)$ (Morgan et al. 1991) together with the $\mathrm{H} 4$ double point mutation (K12Q,K16Q) described above. This form of $\mathrm{H} 3$ mimics an $\mathrm{H} 3$ peptide produced upon digestion of nucleosome core particles with trypsin, and hence this fragment migrates just above H4 in SDS gels (Fig. 3B, arrowhead, lane 1) (Bohm et al. 1981). No binding of Tupl to this truncated form of H3 was observed (Fig. 3B, arrowhead, lane $1^{\prime}$ ), even though higher levels of nonspecific binding to other proteins occurred in this experiment. $\mathrm{H} 3 \operatorname{del}(1-28)$ also failed to bind Tupl-Sepharose columns (data not shown). Taken together, these data indicate that the amino termini of both $\mathrm{H} 3$ and $\mathrm{H} 4$ are critical for mediating interaction with Tupl.

\section{Histone mutations compromise Tup1 function}

If interaction with $\mathrm{H} 3$ and $\mathrm{H} 4$ is important to Tupl function, loss of repression should accompany the loss of Tupl/histone interactions. As described above, H4 $\operatorname{del}(4-19)$, which abolished interaction with Tupl, was shown previously to cause a partial derepression of a cell-specific genes (Roth et al. 1992). Interestingly, whereas both $\mathrm{H} 4$ del(4-14) and $\mathrm{H} 4$ (K16G) exhibited weakened interactions with Tupl, derepression was only observed in the presence of the $\mathrm{H} 4$ (K16G) mutation in previous studies. Perhaps the strong interaction of Tupl with $\mathrm{H} 3$ in these strains can suppress the effects of decreased interaction with $\mathrm{H} 4$ del(4-14) but cannot completely compensate for the weakened interaction with H4 (Kl6G), consistent with the idea that amino acids 15-19 in $\mathrm{H} 4$ are critically important for Tupl binding and function.
To further test the role of histones in Tupl-mediated repression, we examined repression in strains containing the $\mathrm{H} 4$ double point mutation $(\mathrm{K} 12 \mathrm{Q}, \mathrm{K} 16 \mathrm{Q})$, this $\mathrm{H} 4$ mutation in combination with the H3 del(1-28) mutation, and the $\mathrm{H} 3$ del $(1-28)$ mutation alone. The expression of reporter genes responsive to two separate pathways of Tup l-mediated repression, an a cell-specific reporter $(\alpha 2 \mathrm{op}-\mathrm{CYCl}-\mathrm{LacZ})$ and a DNA damage-inducible reporter (RNR2-LacZ), was monitored in the presence of the histone mutations or in isogenic wild-type cells.

As expected, both reporter genes are repressed in the strain containing wild-type $\mathrm{H} 4$ and wild-type $\mathrm{H} 3$ (MSY590 and MSY890; Table 1). A modest (three- to four-fold) derepression of the $\alpha 2$ op-CYCl-LacZ construct is observed in the strain containing the $\mathrm{H} 4$ double point mutation alone (MSY612). We also observed derepression (sixfold) of the $\alpha 2 \mathrm{op}-\mathrm{CYCl}-\mathrm{LacZ}$ reporter in a strain containing $\mathrm{H} 3 \mathrm{del}(1-28)$ and wild-type $\mathrm{H} 4$ (MSY892; Table 1, cf. to MSY 890). Interestingly, elevated expression of an uninduced GALl /glucose-repressible) promoter has also been observed in the presence of H3 amino-terminal deletions (Mann and Grunstein 1992). An even greater derepression of the $\alpha 2$ op-CYCl$\mathrm{LacZ}$ reporter is observed when the $\mathrm{H} 4$ mutation is combined with the $\mathrm{H} 3$ del(1-28) truncation (MSY577; Table 1). $\beta$-Galactosidase expression is increased 13 -fold relative to expression in the wild-type strain. This increase is not observed with a reporter plasmid that is not subject to Tup1 repression (CYC1-LacZ). The expression of the $\mathrm{CYCl}-\mathrm{LacZ}$ reporter is decreased in the presence of the histone mutations, indicating $\mathrm{H} 3$ and $\mathrm{H} 4$ may be important to the activation of this promoter, as has been reported for other genes (Mann and Grunstein 1992; Fisher-Adams and Grunstein 1995). This decrease may also reflect a previously reported requirement of Tupl function for the activation of the CYC1 promoter (Zhang and Guarente 1994). Significantly, $\beta$-galactosidase expression from the $\alpha 20 \mathrm{p}-\mathrm{CYCl}-\mathrm{LacZ}$ reporter in the presence of the combined $\mathrm{H} 3$ and $\mathrm{H} 4$ mutations reaches almost $20 \%$ of the fully nonrepressed level of the CYClLacZ construct in these cells.

Repression of the DNA damage-inducible reporter RNR2-LacZ is also compromised by histone mutation (Table 1B). Again, modest derepression (threefold) is observed in the presence of $\mathrm{H} 3 \operatorname{del}(1-28)$ alone. A greater derepression (ninefold) is observed when this $\mathrm{H} 3$ mutation is combined with the $\mathrm{H} 4\{\mathrm{~K} 12 \mathrm{Q}, \mathrm{K} 16 \mathrm{Q}\}$ mutation, even though this $\mathrm{H} 4$ mutation alone has no effect on the repression of RNR2-LacZ. The greater effect of the coupled mutations on both the a cell-specific and DNA damage-inducible reporter genes is consistent with the combined loss of interaction between Tupl and $\mathrm{H} 3$ del(1-28) and weakened interaction between Tupl and $\mathrm{H} 4$ (K12Q,K16Q) observed above. These results may also indicate a redundancy of $\mathrm{H} 3$ and $\mathrm{H} 4$ functions in Tup1mediated repression. We are currently analyzing several combinations of $\mathrm{H} 3$ and $\mathrm{H} 4$ mutations to further test this idea (W. Zhang and S. Roth, unpubl.). Importantly, the derepression of at least two separate classes of genes regulated by Tupl in the presence of the histone muta- 
Edmondson et al.

Table 1. Histone mutations compromise Tup1 repression

$$
\text { A. a cell-specific reporter }
$$

\begin{tabular}{|c|c|c|c|c|c|}
\hline Strain & $\mathrm{H} 3$ & $\mathrm{H} 4$ & $\alpha 2 o p-C Y C 1-L a c Z$ & $\begin{array}{l}\text { Fold } \\
\text { derepression }\end{array}$ & CYCl-LacZ \\
\hline MSY590 & wild type & wild type & $7 \pm 3$ & 1 & $3533 \pm 1126$ \\
\hline MSY612 & wild type & $\mathrm{K} 12 \mathrm{Q}, \mathrm{K} 16 \mathrm{Q}$ & $24 \pm 1$ & 3 & $2216 \pm 742$ \\
\hline MSY577 & $\operatorname{del}(1-28)$ & $\mathrm{K} 12 \mathrm{Q}, \mathrm{K} 16 \mathrm{Q}$ & $94 \pm 57$ & 13 & $544 \pm 158$ \\
\hline MSY890 & wild type & wild type & $16 \pm 5$ & 1 & N.D. \\
\hline MSY892 & $\operatorname{del}(1-28)$ & wild type & $90 \pm 22$ & 6 & N.D. \\
\hline
\end{tabular}

B. DNA damage-inducible reporter

\begin{tabular}{|c|c|c|c|c|}
\hline Strain & H3 & $\mathrm{H} 4$ & RNR2-LacZ & $\begin{array}{l}\text { Fold } \\
\text { derepression }\end{array}$ \\
\hline MSY590 & wild type & wild type & $16 \pm 14$ & 1 \\
\hline MSY612 & wild type & $\mathrm{K} 12 \mathrm{Q}, \mathrm{K} 16 \mathrm{Q}$ & $9 \pm 10$ & $<1$ \\
\hline MSY577 & $\operatorname{del}(1-28)$ & $\mathrm{K} 12 \mathrm{Q}, \mathrm{Kl} 2 \mathrm{Q}$ & $143 \pm 28$ & 9 \\
\hline MSY890 & wild type & wild type & $57 \pm 15$ & 1 \\
\hline MSY892 & $\operatorname{del}(1-28)$ & wild type & $187 \pm 75$ & 3 \\
\hline
\end{tabular}

$\beta$-Galactosidase activities (expressed as nmoles/min per $\mathrm{mg}$ protein) were determined in cell extracts using ONPG as substrate as described in Materials and methods. Values represent the average of at least two independent transformants and at least three independent assays (in duplicate) of each transformant. Standard deviations | \pm / are as shown. All strains are isogenic. MSY890 and MSY892 carry H3 and H4 genes on a plasmid, whereas these genes are integrated in all other strains.

tions reported here indicates that $\mathrm{H} 3$ and $\mathrm{H} 4$ play a central role in Tupl-mediated repression.

\section{The Tup1 repression domain is required} for interaction with histones $\mathrm{H} 3$ and $\mathrm{H} 4$

Deletion constructs of TUP1 (Fig. 4B) were generated to identify domains that interact with $\mathrm{H} 3$ and $\mathrm{H} 4$. These constructs were translated in vitro and used to probe strips of electroblotted histones (Fig. 4A; summarized in Fig. $4 \mathrm{Cl}$.

We first examined amino-terminal fragments of Tupl for histone-binding activity. A fragment containing amino acids 1-72 exhibited minimal histone binding. Increased binding was observed with a fragment containing amino acids $1-120(27 \%)$, and $82 \%-94 \%$ of fulllength binding was observed with longer fragments containing amino acids $1-253$ or $1-508$. Strong binding was also observed with longer Tupl fragments containing amino acids 1-594 and 1-674 (data not shown). These results indicate the histone-binding domain is located between amino acids 72 and 508 .

We then examined carboxy-terminal fragments of Tupl to determine the carboxy-terminal border of the histone-binding domain. A fragment containing amino acids 316-713 exhibited significant histone binding $(32 \%$ of full length). In agreement with the data presented in Figure 1B, fragments containing amino acids 386-713 or 432-713 exhibited minimal histone-binding activity. These results suggest that the carboxy-terminal boundary of the histone-binding domain extends to amino acid 385 , yet the above studies indicated little difference in the binding of Tupl peptides containing amino acids 1-253 and 1-508. Therefore, we confirmed the histone-binding properties of amino acids carboxyterminal to residue 253 using a bacterially expressed Tupl peptide containing amino acids 252-673. Sepharose beads were coupled to the purified protein and histone binding was assayed as described in Figure 1B. As a control, Sepharose beads were subjected to the same coupling reaction conditions in the absence of added Tupl protein (mock; Fig. 4D). Histones $\mathrm{H} 3$ and $\mathrm{H} 4$ bound to

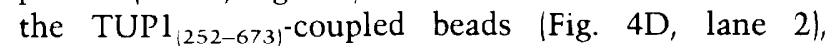
whereas histones $\mathrm{H} 2 \mathrm{~A}$ and $\mathrm{H} 2 \mathrm{~B}$ were found completely in the unbound fraction (Fig. 4D, lane 3; also, cf. to Fig. $1 B$, lanes 4,51 . None of the core histones bound to the mock beads (Fig. 4D, lane 4). As with histones bound to Tup $1_{(72-4.32)}$-coupled beads (Fig. 1B), H3 and $\mathrm{H} 4$ bound to TUPI $_{(252-673)^{-}}$-coupled beads were resistant to elution in up to $0.8 \mathrm{M} \mathrm{NaCl}$ (data not shown), indicating that these interactions are relatively insensitive to ionic conditions. Thus, we conclude that amino acids carboxy-terminal to residue 253 have significant histone-binding activity.

Taken together, our data (Fig. 1B, Fig. 4) indicate that a region of Tupl spanning amino acids 73-385 interacts with histones $\mathrm{H} 3$ and $\mathrm{H} 4$ and that the strongest histonebinding domain is located between amino acids 121 and 316. Previously, repression domains were defined in Tupl between amino acids 72 and 389 (Tzamarias and Struhl 1994). This region mediates all repressive functions of Ssn6/Tupl (Tzamarias and Struhl 1994, 1995) and substantially overlaps the histone-binding domain defined here (Fig. 5), strongly suggesting that Tupl/histone interactions are directly required for Tupl-mediated repression. 


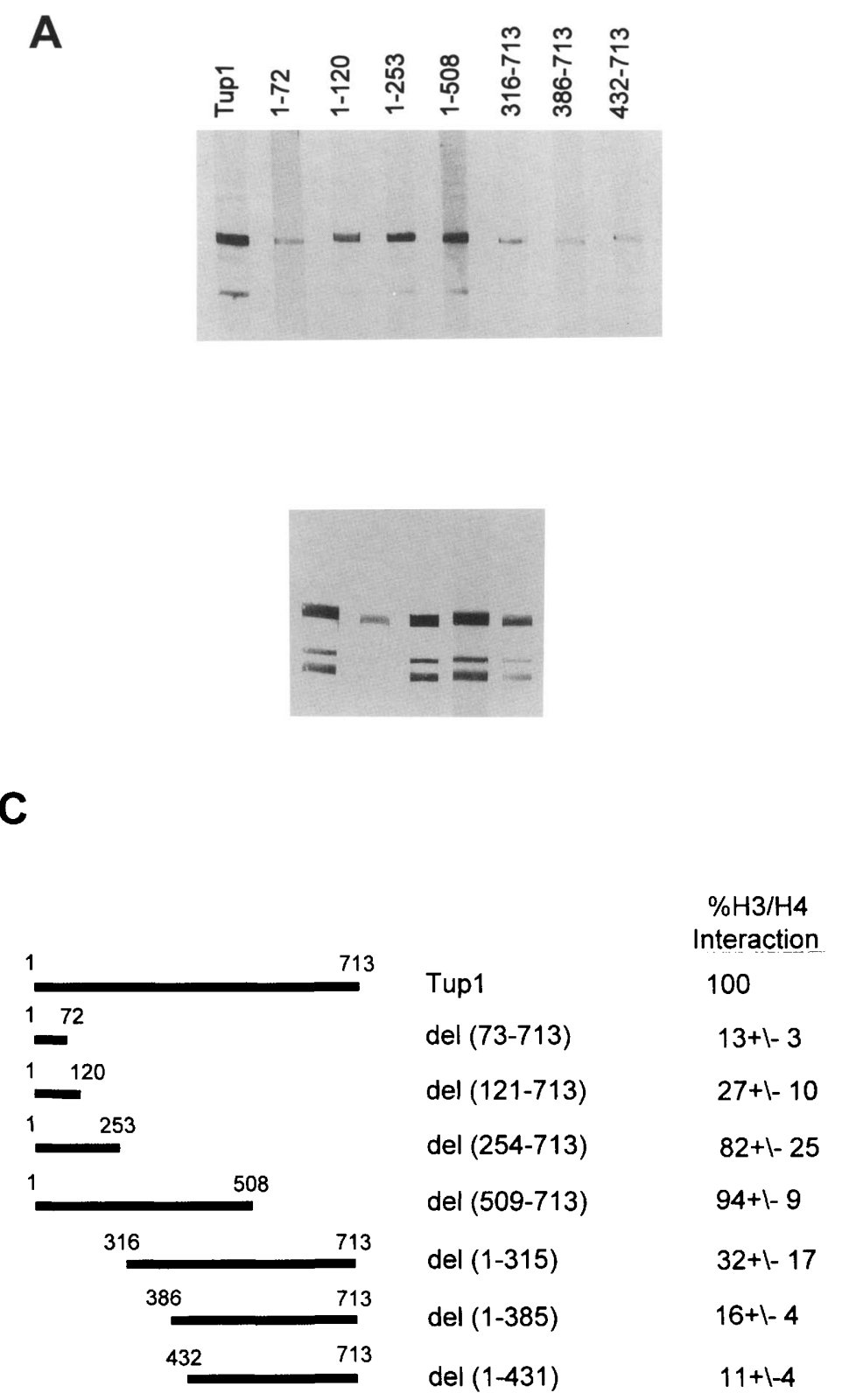

B

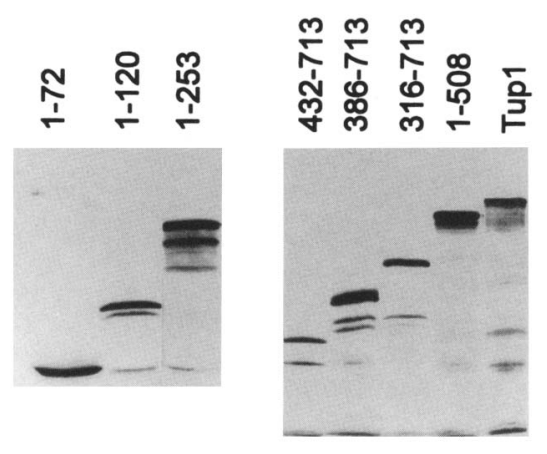

D

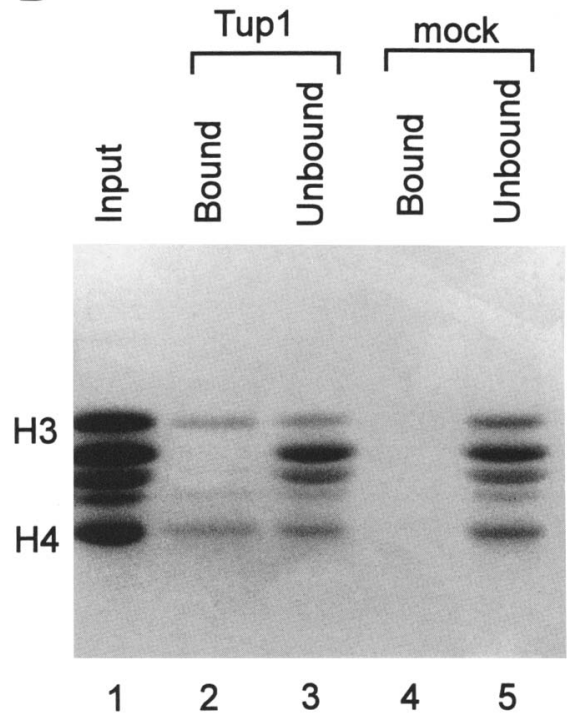

Figure 4. The repression domain of Tupl interacts with histones $\mathrm{H} 3$ and H4. (A) Representative Far Western blot analysis of the ability of various Tupl deletion mutants to bind to H3 and H4. Strips of preparative histone gels were probed with individual Tupl derivatives as indicated at top. Two independent experiments are shown, using different histone preparations and independently translated probes. $(B)$ In vitro-translated probes (as indicated at top) displayed by SDS-PAGE. (Right) An autoradiograph of a $10 \%$ gel; (left) the autoradiograph of a $22 \%$ gel. (C) Summary of the Tupl deletion mutants analyzed, and their ability to interact with $\mathrm{H} 3$ and H4. The structures of Tupl and Tupl deletion derivatives are indicated schematically. Numbers correspond to the amino acids retained in each, and the center column denotes amino acids that are deleted. The right hand column indicates each derivative's ability to interact with $\mathrm{H} 3$ and $\mathrm{H} 4$ relative to intact Tup 1 . Histone binding was quantitated as described in the Materials and methods. $(D)$ Binding of $\mathrm{H} 3$ and $\mathrm{H} 4$ to Tup $1_{(252-673)}-$ Sepharose. Cyanogen bromide-activated Sepharose beads were coupled to purified recombinant Tupl $1_{(252-673)}$ protein or were "mock" coupled in the absence of added protein. Yeast histone samples were added to the beads and allowed to bind. Bound and unbound fractions were then analyzed by SDS-PAGE and Coomassie blue staining. (Lane 1) Input histone protein sample; (lane 2), fraction bound to Tup $1_{(252-673)}$-Sepharose; (lane 3) fraction that did not bind to Tup $\mathbf{1}_{(252-673)}-$ Sepharose; $_{\text {; lane }}$ 4) fraction bound to mock-coupled Sepharose; (lane 5) fraction that did not bind to mock-coupled Sepharose.

\section{Discussion}

Chromatin represses transcription in vivo and in vitro, but often this repression is nonspecific, affecting the basal transcription of most genes, or is associated with specialized heterochromatic structures important for silencing (for review, see Lewin 1994). Our data indicate that chromatin may also be actively recruited by repres- 


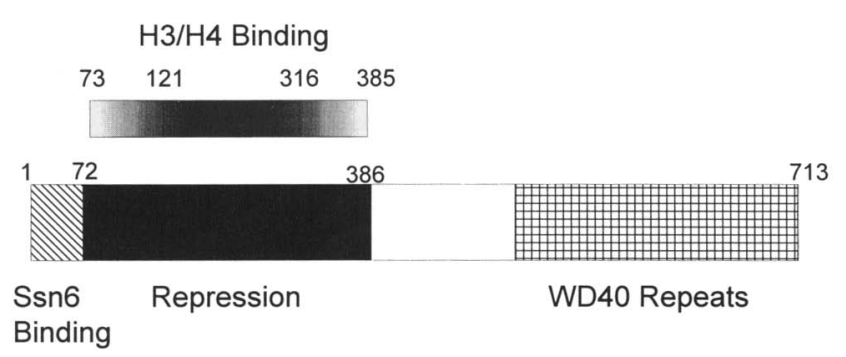

Figure 5. Functional domains of Tup1. The locations of the WD40 repeats, the Ssn6 interaction domain, and the previously defined Tupl repression domain (Komachi et al. 1994; Tzamarias and Struhl 1994, 1995) are shown schematically. The H3/ H4 binding domain defined by this work is depicted above Tupl, showing the correspondence between the histone-binding domain and the repression domain.

sor proteins such as Tupl to establish or maintain repression of specific, euchromatic genes.

\section{Mechanism of repression by Ssn6/Tup1}

Several independent lines of evidence suggest that repression by Ssn6/Tupl is mediated through the organization of chromatin. First, we have demonstrated previously that positioned nucleosomes are linked to the repression of the a cell-specific genes (for review, see Roth 1995). Tupl and Ssn6 are targeted to these promoters via interactions with the cell type-specific repressor $\alpha 2$ (Komachi et al. 1994; Smith et al. 1995), and disruption of either SSN6 or TUP1 leads to loss of positioning as well as loss of repression (Cooper et al. 1994). Organized nucleosomes have also been observed in the promoter region of the glucose-repressible gene SUC2, and this structure is again perturbed by mutations in SSN6 or TUP1 (Matallana 1992). Second, Tupl directly interacts with the amino termini of histones $\mathrm{H} 3$ and $\mathrm{H} 4$, and mutations in these histones that disrupt Tupl/histone interactions cause a partial derepression of both a cell-specific genes and DNA damage-inducible genes. Finally, the histone-binding domain of Tupl overlaps previously defined repression domains (Tzamarias and Struhl 1994, 1995), further suggesting these two Tup1 functions are linked physically.

Although these data strongly indicate that chromatin is important to repression by Tupl, other factors may also contribute. Recently, a CDC28 related kinase $[A R E 1$ (SRB10)] that is part of the yeast RNA polymerase II holoenzyme was identified genetically as a factor required for repression of the a cell-specific genes (Kuchin et al. 1995; Wahi and Johnson 1995), suggesting that Tupl might interact directly with general transcription factors. However, many kinases have multiple targets in the cell, and phosphorylation of a factor, perhaps even Ssn 6 or Tup1, may be required to stabilize interactions between Tupl and neighboring nucleosomes. Alternately, Tupl might interact with general transcription factors to initiate repression and subsequently organize chromatin to maintain the repressed state.

\section{The Tup1 histone-binding domain}

The domain in Tupl that exhibits strongest binding to histones $\mathrm{H} 3$ and $\mathrm{H} 4$ (amino acids 121-385) contains few charged residues. The absence of an acidic region in the histone-binding domain and the stability of Tup1-H3/ $\mathrm{H} 4$ interactions in high salt argues against a nonspecific electrostatic association between these proteins, as does the lack of Tupl interaction with other highly charged proteins such as $\mathrm{H} 2 \mathrm{~A}, \mathrm{H} 2 \mathrm{~B}$, and lysozyme. The Tupl histone-binding domain is rich in proline, serine, and alanine (Williams and Trumbly 1990). Remarkably, 27 of the 35 proline residues in Tupl are located in this interval. A stretch rich in glutamine is also found in the strong histone-binding domain (amino acids 181-198), but a longer glutamine repeat is found upstream (amino acids $97-118$ ) in a region that binds less well to histones. At present, it is unclear what features of the histonebinding domain are important for interaction with $\mathrm{H} 3$ and $\mathrm{H} 4$. No obvious homologies between this region and histone-binding domains defined in other proteins, such as N1 (Kleinschmidt and Seiter 1988) or Sir3 (Hecht et al. 1995), have been detected.

The ability of Tupl to interact with the spontaneously generated fragment of histone $\mathrm{H} 3\left(\mathrm{H}_{3}{ }^{*}\right.$; Fig. 1A) present in some of our histone preparations but not the genetically engineered H3 amino-terminal deletion suggests that a very specific region within the $\mathrm{H} 3$ amino terminus is required for interaction with Tupl. The "autolytic" H3 fragment has been identified as a peptide containing amino acids 21-135 or 23-135 (Bohm et al. 1981; Bortvin and Winston 1996), whereas the genetically engineered truncation only contains amino acids 29-135 (Morgan et al. 1991). Amino acids 21-28 of histone H3, therefore, may be critical for the Tupl/H3 interaction. Interestingly, this domain contains two potential sites of acetylation, as well as a potential phosphorylation site.

\section{Mechanism of nucleosome positioning}

Our data suggest a molecular model for positioning of nucleosomes adjacent to the $\alpha 2$ operator (Fig. 6). Recruitment of Ssn6/Tupl by $\alpha 2$ most likely establishes the position of the first nucleosome through Tupl/histone interactions. Multimerization of Tupl or of Ssn6/Tupl complexes might then provide a template for the propagation of positioned nucleosomes farther downstream. Ssn 6 has been proposed to interact with Tupl multimers (Tzamarias and Struhl 1995) and could conceivably serve as a framework for the stabilization of Tupl polymers that in turn could propagate nucleosome positioning. Such a framework would help to explain the extent of the positioned arrays observed adjacent to the $\alpha 2$ operator $(>3 \mathrm{~kb}$ at STE6; Simpson et al. 1993). Loss of Ssn6, then, would be predicted to destabilize positioning, whereas loss of Tupl would be predicted to cause more drastic alterations in nucleosome locations. These predictions are consistent with changes observed in the chromatin structure of STE6 in the absence of Ssn 6 or Tupl (Cooper et al. 1994). 


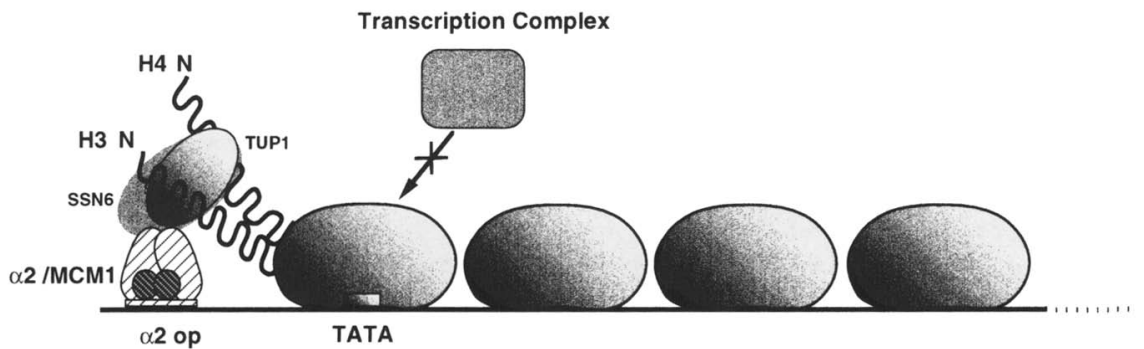

Figure 6. Model for Tupl-mediated nucleosome positioning. The Ssn6/Tup1 repressor complex is recruited to promoters of a cell-specific genes via direct interaction with $\alpha 2$. Tupl then serves as a "bridge" between $\alpha 2 / M C M 1$ and the neighboring nucleosome through interactions with the amino termini of $\mathrm{H} 3$ and $\mathrm{H} 4$, nucleating an array of positioned nucleosomes adjacent to the $\alpha 2 / \mathrm{MCM} 1$ binding site. Ssn6/Tupl multimers may also play a role in the propagation of the positioned nucleosomes downstream (see text). The positioned nucleosome array contributes to repression by blocking access to transcription factors.

\section{Different targets, different structures?}

Ssn6/Tupl complexes are targeted to different promoters by specific DNA-binding proteins, and it is clear that different regions of Ssn6 and/or Tup1 are required for repression of different sets of genes (Tzarmarias and Struhl 1995). The combinatorial nature of this repression may be somewhat analogous to the combinatorial action of some transcriptional activators. In both cases, different partners are utilized to direct the regulation of particular promoters. It remains to be seen whether the modularity of Ssn6/Tupl repression is reflected in a range of different chromatin structures organized by these factors. For example, the positioning of nucleosomes at the a cell-specific genes might be established through the recruitment of two Ssn6/Tupl complexes by the homodimer of $\alpha 2$ bound to the $\alpha 2$ operator. Alternatively, one molecule of $\alpha 2$ may interact with Ssn6, whereas the other interacts with Tupl, increasing the affinity of Ssn6/Tupl binding at a cell-specific promoters and leading to the highly organized chromatin structures associated with these genes. Interactions between Ssn6/Tupl and other DNA-binding factors may occur with different affinities and/or stoichiometries, leading to less stable or more accessible structures associated with inducible genes. Moreover, the binding of Tupl to less highly acetylated isoforms of $\mathrm{H} 3$ and $\mathrm{H} 4$ suggests a pathway by which chromatin-induced repression might be reversed in response to changing cellular needs. Further characterization of the interactions between Ssn6/ Tupl and various DNA-binding factors and further examination of the chromatin structures of genes regulated by these factors will determine the validity of these speculations.

\section{Relevance to other repressors}

$\mathrm{H} 3$ and $\mathrm{H} 4$ participate in silencing at telomeres and the silent mating loci (Kayne et al. 1988; Thompson et al. 1994) through interactions with two regulatory proteins, Sir3 and Sir4 (Johnson et al. 1990; Hecht et al. 1995). Like Ssn6/Tup1, these proteins are targeted to specific sites via interactions with DNA-binding proteins (for review, see Roth 1995). Sir3/Sir4 complexes then cooperate with other silencing factors to nucleate a silenced chromatin domain. Recruitment of specialized chromatin "organizers" to specific promoters may be a common mechanism of transcriptional repression.

The histones and, in particular, the amino termini of histones $\mathrm{H} 3$ and $\mathrm{H} 4$ are highly conserved between species, raising the possibility that interactions between transcriptional repressors and histones might also occur in other systems. The Polycomb group genes (PcG) in Drosophila provide intriguing candidates for this type of regulation. (for review, see Orlando and Paro 1995). These genes repress homeotic genes and other developmental regulatory factors to aid in the establishment of body pattern and segmentation. A mammalian homolog, $B m i-1$, has been identified, and bmi-1-deficient mice suffer homeotic transformations similar to those caused by PcG mutations in flies (Van der Lugt et al. 1994). Like Ssn6/Tupl, the PcG genes form a complex that may be targeted to genes through interactions with specific DNA-binding proteins such as hunchback. Repression of Ultrabithorax by hunchback has been proposed to involve a specialized chromatin structure established by PcG complexes (Bienz 1992). Moreover, the PcG protein extra sex combs contains multiple WD repeats (Sathe and Harte 1995). It will be interesting to determine whether these complexes also interact with nucleosomes via specific interactions with histones $\mathrm{H} 3$ and $\mathrm{H} 4$.

Interactions between Ssn6/Tupl and the histones furnish a physical and functional link between transcriptional regulators and chromatin. Post-translational modifications such as acetylation and phosphorylation may be used to fine tune this regulation and make it responsive to environmental or developmental cues. These global regulators provide important clues as to how chromatin may be remodeled to reprogram gene expression.

\section{Materials and methods}

Yeast strains

Saccharomyes cerevisiae strains were propagated according to standard procedures (Rose et al. 1990) in either rich media (YEPD) or selective media (SC lacking the appropriate amino 
Table 2. Strain list

\begin{tabular}{|c|c|c|}
\hline Strain & Genotype & Reference \\
\hline PKY999 & 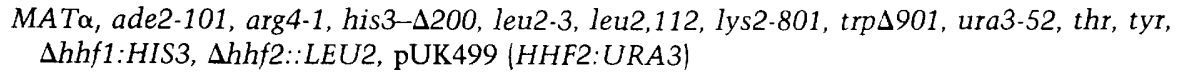 & Kayne et al. (1988) \\
\hline PK917 & isogenic to PKY999 except pPK917[hhf2 del(4-14)] instead of pUK499 & Kayne et al. (1988) \\
\hline PKY918 & isogenic to PKY999 except pPK918[hhf2 del(4-19):URA3] instead of pUK499 & Kayne et al. (1988) \\
\hline PKY505 & isogenic to PKY999 except MATa and pPK305[hhf2 Gly-16 URA3] instead of pUK499 & Johnson et al. (1990) \\
\hline MSY590 & MAT $\alpha$, ura3-52, lys2- $\Delta 201$, leu2-3, HHT1, HHF1 $\Delta(h h t 2-h h f 2)$ & Megee et al. $\{1995\}$ \\
\hline MSY $577^{\mathrm{a}}$ & $\begin{array}{l}\text { isogenic to MSY590 except Mata, hht1-2 del(1-28), hhf1-32(H4 K12Q,K16Q) instead of } \\
\text { HHT1, HHF1 }\end{array}$ & P. Megere and M. Smith \\
\hline MSY612 ${ }^{\mathrm{a}}$ & isogenic to MSY590 except MATa, hhf1-32 instead of $H H F 1$ & Megee et al. (1995) \\
\hline MSY890 & $\begin{array}{l}\text { MATa, ura3-52, leu2-3,-112 lys2 } 201 \Delta(h h t 1 \text { hhf1) } \Delta(h h t 2 \text { hhf2) pMS337|CEN ARS LEU2 } \\
\text { hht1-1 HHF1] }\end{array}$ & Morgan et al. (1991) \\
\hline MSY892 & isogenic to MSY890 except pMS358[CEN ARS LEU2 hht1-2 HHF1] instead of pMS337 & Morgan et al. (1991) \\
\hline YPH49 & MATa/a ura3-52/ura3-52, ade2-101/ade2-101, lys2-801/lys2-801, $\operatorname{trp} 1 \Delta 1 / \operatorname{trp} 1 \Delta 1$ & Rose et al. (1990) \\
\hline
\end{tabular}

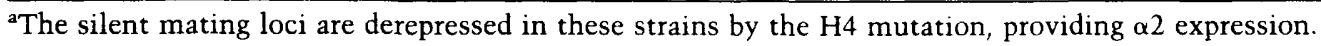

acids). Strains used are presented in Table 2. Yeast were transformed with various plasmids according to Hill et al. (1991).

\section{Plasmids}

\section{Tup1 constructs}

A PstI-HindIII fragment of the Tupl clone pFW28 (Williams and Trumbly 1990) was excised and cloned into the PstI-HindIII sites of pBluescript II (Stratagene). An oligomer corresponding to nucleotides $478-492$ of Tupl with NcoI and Xhol sites on the $5^{\prime}$ end and the KS primer (Stratagene) were used to PCR a fulllength copy of Tupl, which was then cloned into the NcoI and Sall site of pCITE2 (Novagen). Tup1 truncations were made as follows: Tup1-72, Tup1-119, Tup1-253, Tup1-506, Tup1-594, and Tupl-674 were made by cloning the NcoI-MluI, the NcoINheI, the NcoI-BamHl, the NcoI-BstEII, the NcoI-BglII, and the NcoI-EcoRI fragments from pCite/Tupl into the NcoI-BglII sites of pCITE2 (the 3 ' junction between the Tupl deletion and pCITE was blunted when the fragments did not have complementary ends|. The remaining Tupl deletion clones were generated by PCR with oligomers corresponding to the appropriate Tupl sequences and engineered to contain restriction sites for cloning and were cloned into either the NcoI-SalI sites or the NcoI-BamHl sites of pCITE2.

For bacterial expression of Tupl, three clones were constructed by cloning Tupl fragments into the pRset vector (Invitrogen). A BamHI-EcoRI fragment of Tupl was used to construct Tupl $l_{(252-673\}}$, whereas DNA fragments corresponding to $\operatorname{Tupl}_{(72-432)}$ and Tupl $1_{(459-713)}$ were generated by PCR with oligomers containing the appropriate Tupl sequences. The fusion proteins produced by these vectors have a "histidine" tag fused to the amino terminus.

\section{$\beta$-Galactosidase reporter constructs}

The RNR2-LacZ (pNN405) construct was generously provided by S. Elledge (Elledge and Davis 1989). The CYCl-LacZ construct was a generous gift of D. Stillman (University of Utah, Salt Lake City) (plasmid pM629). A double-stranded oligonucleotide corresponding to the $\alpha 2$ operator present in the STE6 promoter was cloned into a unique Sall site in M629, such that the operator was inserted between the UAS and TATA sequences in the $\mathrm{CYCl}$ promoter (plasmid pM629 ${ }_{\alpha 2 \mathrm{op}}$ ).

\section{Histone purification}

Histones were isolated from YPH49 or other strains in Table 2 by a combination of procedures described by Braunstein et al. (1993) and Davie et al. (1981). One or two liters of yeast were grown to a density of $\sim 2 \times 10^{8}$ cells $/ \mathrm{ml}$ and centrifuged in a Beckman JA-10 rotor for $5 \mathrm{~min}$ at $5000 \mathrm{rpm}$ at $4^{\circ} \mathrm{C}$. The cell pellet was washed once in sterile water, then resuspended in 50 $\mathrm{ml}$ of $0.1 \mathrm{mM}$ Tris (pH 9.4), $10 \mathrm{~mm}$ DTT and incubated for 15 min at $30^{\circ} \mathrm{C}$ with gentle shaking. The cells were centrifuged as above, washed in $100 \mathrm{ml}$ of $1.2 \mathrm{M}$ Sorbitol, $20 \mathrm{~mm}$ HEPES (pH 7.4), respun, then resuspended in the same buffer with $2 \mathrm{ml}$ of $10 \mathrm{mg} / \mathrm{ml}$ Zymolyase. Cells were incubated at $30^{\circ} \mathrm{C}$ for $45-60$ min with gentle shaking, until they could be easily "squashed" between a glass slide and coverslip (Roth and Simpson 1992). Following the addition of $100 \mathrm{ml}$ of ice-cold $1.2 \mathrm{M}$ Sorbitol, 20 $\mathrm{mm}$ PIPES, $1 \mathrm{~mm} \mathrm{MgCl}_{2}$ (pH6.8), the cells were centrifuged again in a JA 10 rotor $\left(5 \mathrm{~min}, 4^{\circ} \mathrm{C}, 3.5 \mathrm{~K}\right)$. Cell pellets were resuspended in $50 \mathrm{ml}$ of ice-cold NIB (nuclei isolation buffer; $0.25 \mathrm{M}$ sucrose, $60 \mathrm{mM} \mathrm{KCl}, 14 \mathrm{mM} \mathrm{NaCl}, 5 \mathrm{mM} \mathrm{MgCl}, 1 \mathrm{mM} \mathrm{CaCl}_{2}, 15$ mM MES at pH 6.6, 1 mM PMSF, $0.8 \%$ Triton X-100), held on ice water for $20 \mathrm{~min}$, and spun at $4 \mathrm{~K}$ in a JA10 rotor for $5 \mathrm{~min}$. The NIB wash was repeated two times. The cells were then washed three times in "A" wash (10 mM Tris at $\mathrm{pH} 8.0,0.5 \%$ NP-40, 75 $\mathrm{mm} \mathrm{NaCl}, 30 \mathrm{~mm}$ sodium butyrate, $1 \mathrm{~mm}$ PMSF; Davie et al. 1981), holding on ice water for $15 \mathrm{~min}$ for the first two washes and $5 \mathrm{~min}$ for the final wash. The cell pellet was then washed in "B" wash $10 \mathrm{~mm}$ Tris at $\mathrm{pH} 8.0,0.4 \mathrm{M} \mathrm{NaCl}, 30 \mathrm{~mm}$ sodium butyrate, $1 \mathrm{~mm}$ PMSF; Davie et al. 1981) one time for $10 \mathrm{~min}$ holding on ice water. After centrifugation, the cells were resuspended again in B buffer and centrifuged immediately. The histones were extracted by resuspending the pellet in $10 \mathrm{ml}$ of cold $0.4 \mathrm{~N} \mathrm{H}_{2} \mathrm{SO}_{4}$ and holding in ice water for $30 \mathrm{~min}$, vortexing occasionally. Debris was removed from the solution by spinning for $10 \mathrm{~min}$ at $10 \mathrm{~K}$. The supernatant, which contains the extracted histones, was precipitated by adding $100 \%$ TCA to a final concentration of $20 \%$. After $30 \mathrm{~min}$ incubation in ice water, the protein pellet was collected by centrifugation for 30 min, at $12 \mathrm{~K}$ in a Beckman JS 13.1 rotor. Pellets were washed in acidified acetone (acetone $+1 \% \mathrm{HCl}$ ), then acetone, and then air dried. The histones were resuspended in $\sim 2 \mathrm{ml}$ of $10 \mathrm{~mm}$ Tris $(\mathrm{pH} 8.0)$ and stored at $-20^{\circ} \mathrm{C}$. 


\section{Far Western blot analysis}

Proteins were separated by SDS-PAGE as described (Allis et al. 1980; Allis and Wiggins 1984 (22\% gel, 60:0.4 acrylamide/ bisacrylamide)]. After equilibration in transfer buffer (running buffer plus $10 \%$ methanol), gels were semidry-blotted (Fisher Scientific; $2 \mathrm{hr}$ at $500 \mathrm{~mA}$ ) to polyvinylidene difluoride (PVDF) membrane (MSI) that was prewet in methanol and then equilibrated in transfer buffer. After transfer, the blots were stained for 10 min with Ponceau Red (Sambrook et al. 1989) and the positions of the histone bands were marked. The blots were then blocked for $2 \mathrm{hr}$ in $0.05 \%$ Tween 20 in PBS $(137 \mathrm{mM} \mathrm{NaCl}$, $3 \mathrm{mM} \mathrm{KCl}, 7 \mathrm{mM} \mathrm{Na}_{2} \mathrm{HPO}_{4}, 15 \mathrm{mM} \mathrm{K}_{2} \mathrm{HPO}_{4}$ at $\mathrm{pH} 7.9-8.0$ ), for $2 \mathrm{hr}$ in $1 \% \mathrm{BSA}$ in PBS, then rinsed for $10 \mathrm{~min}$ in phosphatebuffered saline (PBS) (Kleinschmidt and Seiter 1988). Blots were then wrapped in plastic wrap and stored overnight to 2 weeks at $4^{\circ} \mathrm{C}$.

Full-length Tupl or deletion derivatives were translated in vitro in the presence of ${ }^{35} \mathrm{~S}$-methionine using the Promega TnTcoupled transcription/translation kit. Probes were diluted with $400 \mu l$ of $1 \times$ Promega translation buffer or with $40 \mathrm{~mm}$ HEPES (pH 7.4), 40 mM DTT, placed in a microcon 10 (Amicon) column, and spun for $20 \mathrm{~min}$ at $10,000 \mathrm{~g}$ in a microcentrifuge at room temperature. An aliquot of the purified probe (typically $2 \mu \mathrm{l}$ ) was analyzed by SDS-PAGE, and a separate aliquot was taken for scintillation counting. The remaining probe was diluted in 3 $\mathrm{ml}$ of $\mathrm{PBS}$ containing $1 \%$ goat serum, $0.3 \%$ BSA. Blots were prehybridized for $10 \mathrm{~min}$ in this buffer without probe, then incubated for $2 \mathrm{hr}$ at room temperature in a $50-\mathrm{ml}$ conical tube containing the probe. The tubes were mechanically rotated throughout the binding reaction. After $2 \mathrm{hr}$, blots were washed in PBS for $4 \times 5 \mathrm{~min}$, allowed to air dry, then exposed to film or to PhosphorImager screens (Molecular Dynamics).

Quantitation of full-length Tupl binding to mutant histone $\mathrm{H} 4$ proteins (as in Fig. 3) was performed by densitometric scanning of Coomassie-stained histone gels and autoradiographs of corresponding FAR Western blots. The signal in the $\mathrm{H} 4$ region of the FAR Western blot was normalized according to the $\mathrm{H} 4$ signal in the corresponding stained gel to determine the level of Tupl binding/load of H4. Binding of Tupl to each mutant form of $\mathrm{H} 4$ was then normalized to that of Tupl binding to wild-type $\mathrm{H} 4$ (set at $100 \%$ ).

Quantitation of Tup1 fragment binding to wild-type histones (as in Fig. 4) was performed with Molecular Dynamics ImageQuant software. In this case, strips of preparative histone blots containing equal loads of histone (within each experiment) were probed with different Tupl fragments and the level of $\mathrm{H} 3 / \mathrm{H} 4$ binding by full-length Tup1 was set to $100 \%$. The data summarized in Figure 4C represent the average of at least three (more typically five) independent FAR Western blots for each Tupl probe. All probes were translated to similar specific activities, and differential binding of the Tupl derivatives to $\mathrm{H} 3$ and $\mathrm{H} 4$ was not a function of differential labeling owing to methionine content. For example, the 1-72, 1-120, and 1-253 Tupl constructs all contain the same three methionine residues |positions 45,52 , and 69 , yet the $1-253$ fragment exhibited significantly more histone binding than did the other two fragments.

\section{Tup1-Sepharose affinity chromatography}

The Tupl fusion proteins were expressed in bacterial cells [BL21(DE3)] and purified using Novagen His-Bind resin and buffers according to the manufacturer-supplied procedures. The Tup $l_{(72-432)}$ protein was isolated under nondenaturing conditions. The $\operatorname{Tupl}_{(252-673)}$ and $\operatorname{Tupl}_{(459-713)}$ fusion proteins were isolated in $6 \mathrm{M}$ urea using the denaturing protocol. The proteins were renatured by sequential dialysis through $4 \mathrm{M}, 2 \mathrm{M}$, and $1 \mathrm{M}$ urea in PBS and then through several changes of PBS.

Cyanogen bromide-activated Sepharose beads were purchased from Pharmacia, and Tupl proteins were coupled to the beads as described in Harlow and Lane (1988). Histone proteins in binding buffer $(20 \mathrm{~mm}$ Tris at $\mathrm{pH} 8.0,150 \mathrm{~mm} \mathrm{NaCl}, 1 \mathrm{~mm}$ EDTA, $0.1 \%$ Triton X-100, $1 \mathrm{~mm}$ glutamate, $1 \mathrm{~mm}$ DTT) were added to $\sim 25 \mu \mathrm{l}$ of Tupl-beads or mock-coupled beads that had been washed extensively in binding buffer. After incubation at room temperature for 5-15 min, beads were collected by centrifugation (microcentrifuge at $700 \mathrm{~g}$ for $2 \mathrm{~min}$, room temperature). The supernatant was saved (unbound fraction), and the beads were washed for $3 \times 5 \mathrm{~min}$ with $1 \mathrm{ml}$ of binding buffer. For salt wash experiments, beads were washed two times in binding buffer followed by a wash in binding buffer containing 0.4 or $0.8 \mathrm{M}$ $\mathrm{NaCl}$. The washed beads were resuspended directly in $2 \times$ SDSPAGE buffer, and all samples were analyzed by SDS-PAGE and visualized by staining with Coomassie Brilliant blue R (Sambrook et al. 1989).

\section{$\beta$-Galactosidase assays}

$\beta$-Galactosidase activities of reporter genes in wild-type cells or in strains carrying histone mutations were quantitated by standard ONPG (O-nitrophenyl- $\beta$-D-galactoside) assays following preparation of cell extracts by a glass bead procedure (Rose et al. 1990 ).

\section{Preparation of antibodies to acetylated $\mathrm{H} 3$}

A peptide corresponding to the first 20 amino acids of yeast histone $\mathrm{H} 3$ with acetyl groups arbitrarily placed at lysines 9 and 18 was purchased (Baylor College of Medicine Protein Chemistry Core Facilityl and used to generate polyclonal rabbit antibodies (Bethyl Laboratories).

\section{Acid-urea gels}

Acid-urea gels were prepared and run according to Allis et al. (1980). After an overnight "preelectrophoresis," the gels were warmed to room temperature and "teeth" were cast. The gels were then "scavenged" for $1 \mathrm{hr}$ with $20 \mu \mathrm{l}$ of $8 \mathrm{M}$ urea, $5 \%$ acetic acid, $0.6 \mathrm{M} \beta$-mercaptoethanol. Approximately $50 \mu \mathrm{g}$ of histone preparation [TCA precipitated and resuspended in loading buffer $14 \mathrm{M}$ urea, $0.02 \%$ pyronin $\mathrm{Y}, 4 \% \beta$-mercaptoethanol, $5 \%$ acetic acid)| was loaded per lane, and $31-\mathrm{cm}$ gels were run for $17,000 \mathrm{Vh}$ at $4^{\circ} \mathrm{C}$. After electrophoresis, gels were equilibrated in $0.7 \%$ acetic acid, then semidry-blotted in the same buffer, or were stained with Coomassie Brilliant blue R. Blotted membranes were processed for either FAR Western or traditional Western blot analysis.

\section{Western blots}

Blotted PVDF membranes were blocked for $2 \mathrm{hr}$ to overnight in $5 \%$ Carnation nonfat dry milk in TBS $(10 \mathrm{~mm}$ Tris at pH 7.5, 150 $\mathrm{mm} \mathrm{NaCl})$. Membranes were then incubated at $37^{\circ} \mathrm{C}$ overnight with either anti-acetylated $\mathrm{H} 3$ antibodies $(1: 1000$ dilution in $1 \times$ TBS with $1 \%$ goat serum and $0.3 \%$ BSA) or anti-acetylated $\mathrm{H} 4$ antibodies |"penta," Lin et al. 1989) (1:500 dilution). The next day, membranes were washed $6 \times 5 \mathrm{~min}$ with $1 \times$ TBS prior to incubation with $1: 1000$ dilution of goat anti-rabbit IgG, conjugated to alkaline phosphatase (Boehringer Mannheim) in TBS with $10 \%$ goat serum. Membranes were then washed again $16 \times$ $5 \mathrm{~min}$ in $1 \times \mathrm{TBS})$ and were developed with $66 \mu \mathrm{l}$ of NBT $(5 \%$ stock in $70 \%$ dimethylformamide $)$ and $33 \mu$ of BCIP $[5 \%$ in 
dimethylformamide) per $10 \mathrm{ml}$ of alkaline phosphatase buffer (100 $\mathrm{mm}$ Tris at $\mathrm{pH} 9.5,10 \mathrm{~mm} \mathrm{NaCl}, 5 \mathrm{~mm} \mathrm{MgCl}_{2}$ ).

\section{Acknowledgments}

We thank the following researchers for their generous gifts: Robert Trumbly for the pFW28 plasmid, Steven Elledge for the plasmid pNN405, D. Stillman for the plasmid M629, Michael Grunstein for the PKY999, PKY918, PKY917, and PKY505 yeast strains, Paul Megee for construction of strain MSY577, David Allis for the penta (anti-acetylated H4) antibody, and Jerry Workman, Dave Allis, and Van Moudrianakis for histones. We also thank Tim Macatee and Olga Yarygina for their invaluable technical assistance and Alisha Tizenor for help with graphics. We are grateful to David Roth for reading of the manuscript. This work was supported by grants from the National Institutes of Health (NIH) [RO1-GM511890 (S.Y.R.) and R01-GM28920 (M.M.S.|] and the Texas Higher Education Coordinating Board (ARP 095) and by the UTMDACC Core Support Grant P30CA16672. D.G.E. was supported by an NIH training grant (T32HD07325) and an individual NIH-NRSA (CA65098-01).

The publication costs of this article were defrayed in part by payment of page charges. This article must therefore be hereby marked "advertisement" in accordance with 18 USC section 1734 solely to indicate this fact.

\section{References}

Allis, C.D. and J.C. Wiggins. 1984. Histone rearrangements accompany nuclear differentiation and dedifferentiation in Tetrahymena. Dev. Biol, 101: 282-294.

Allis, C.D., C.V. Glover, J.K. Bowen, and M.A. Gorovsky. 1980. Histone variants specific to the transcriptionally active, amitotically dividing macronucleus of the unicellular eucaryote, Tetrahymena thermophila. Cell 20: 609-617.

Bienz, M. 1992. Molecular mechanism of determination in Drosophila. Curr. Opin. Cell Biol. 4: 955-961.

Bohm, L., G. Briand, P. Sauthere, and C. Crane-Robinson. 1981. Proteolytic digestion studies of chromatin core-histone structure. Identification of the limit peptides of histones $\mathrm{H} 3$ and H4. Eur. J. Biochem. 119: 67-74.

Bone, J.R., J. Lavender, R. Richman, M.J. Palmer, B.M. Turner, and M.I. Kuroda. 1994. Acetylated histone H4 on the male X chromosome is associated with dosage compensation in Drosophila. Genes \& Dev. 8: 96-104.

Bortvin, A. and F. Winston. 1996. Evidence that Spt6p controls chromatin structure by a direct interaction with histones. Science (in press).

Braunstein, M., A.B. Rose, S.G. Holmes, C.D. Allis, and J.R. Broach. 1993. Transcriptional silencing in yeast is associated with reduced nucleosome acetylation. Genes \& Dev. 7: 592604.

Carlson, M., B.C. Osmond, L. Neigeborn, and D. Botstein. 1984. A suppressor of snf1 mutations causes constitutive highlevel invertase synthesis in yeast. Genetics 107: 19-32.

Cooper, J.P., S.Y. Roth, and R.T. Simpson. 1994. The global transcriptional regulators, SSN6 and TUP1, play distinct roles in the establishment of a repressive chromatin structure. Genes \& Dev. 8: 1400-1410.

Davie, J.R., C.A. Saunders, J.M. Walsh, and S.C. Weber. 1981. Histone modifications in the yeast $S$. cerevisiae. Nucleic Acids Res. 9: 3205-3216.

Elledge, S.J. and R.W. Davis. 1989. DNA damage induction of ribonucleotide reductase. Mol. Cell. Biol. 9: 4932-4940.
Fisher-Adams, G. and M. Grunstein. 1995. Yeast histone H4 and $\mathrm{H} 3 \mathrm{~N}$-termini have different effects on the chromatin structure of the GAL1 promoter. EMBO /. 14: 1468-1477.

Fong, H.K.W., J.B. Hurley, R.S. Hopkins, R. Miake-Lye, M.S. Johnson, R.F. Doolittle, and M. Simon. 1986. Repetitive segmental structure of the transducin $\beta$ subunit: Homology with the CDC4 gene and identification of related mRNAs. Proc. Natl. Acad. Sci. 83: 2162-2166.

Harlow, E. and D. Lane. 1988. Antibodies: A laboratory manual. Cold Spring Harbor Laboratory, Cold Spring Harbor, NY.

Hecht, A., T. Laroche, S. Strahl-Bolsinger, S.M. Gasser, and M. Grunstein. 1995. Histone $\mathrm{H} 3$ and $\mathrm{H} 4 \mathrm{~N}$-termini interact with Sir3 and Sir4 proteins: A molecular model for the formation of heterochromatin in yeast. Cell 80: 583-592.

Herschbach, B.M., M.B. Arnaud, and A.D. Johnson. 1994. Transcriptional repression directed by the yeast $\alpha 2$ protein in vitro. Nature 370: 309-311.

Hill, J., I.G. Donald, and D.E. Griffiths. 1991. DMSO enhanced yeast transformation. Nucleic Acids Res. 19: 5791.

Hirschhorn, J.N., S.A. Brown, C.D. Clark, and F. Winston. 1992. Evidence that $S N F 2 / S W I 2$ and SNF5 activate transcription in yeast by altering chromatin structure. Genes \& Dev. 6: $2288-2298$.

Jeppesen, P. and B.M. Turner. 1993. The inactive X chromosome in female mammals is distinguished by a lack of histone $\mathrm{H} 4$ acetylation, a cytogenetic marker for gene expression. Cell 74: $281-289$.

Johnson, L.M., P.S. Kayne, E.S. Kahn, and M. Grunstein. 1990. Genetic evidence for an interaction between SIR3 and histone $\mathrm{H} 4$ in the repression of silent mating loci in Saccharomyces cerevisiae. Proc. Natl. Acad. Sci. 87: 6286-6290.

Kayne, P.S., U. Kim, M. Han, J.R. Mullen, F. Yoshizaki, and M. Grunstein. 1988. Extremely conserved histone H4 N terminus is dispensable for growth but essential for repressing the silent mating loci in yeast. Cell 55: 27-39.

Keleher, C.A., M.J. Redd, J. Schultz, M. Carlson, and A.D. Johnson. 1992. SSN6-TUPl is a general repressor of transcription in yeast. Cell 68: 709-719.

Kleinschmidt, J.A. and A. Seiter. 1988. Identification of domains involved in nuclear uptake and histone binding of protein N1 of Xenopus laevis. EMBO /. 7: 1605-1614.

Komachi, K., M.J. Redd, and A.D. Johnson. 1994. The WD repeats of TUP1 interact with the homeo domain protein $\alpha 2$. Genes \& Dev. 8: 2857-2867.

Kuchin, S., P. Yeghiayan, and M. Carlson. 1995. Cyclin-dependent protein kinase and cyclin homologs SSN3 and SSN8 contribute to transcriptional control in yeast. Proc. Natl. Acad. Sci. 92: 4006-4010.

Lewin, B. 1994. Chromatin and gene expression: Constant questions but changing answers. Cell 79: 397-406.

Lin, R., J.W. Leone, R.G. Cook, and C.D. Allis. 1989. Antibodies specific to acetylated histones document the existence of deposition- and transcription-related histone acetylation in Tetrahymena. I. Cell Biol. 108: 1577-1588.

Mann, R.K. and M. Grunstein. 1992. Histone H3 N-terminal mutations allow hyperactivation of the yeast GAL1 gene in vivo. $E M B O$ I. 11: 3297-3306.

Matallana, E., L. Franco, and J.E. Perez-Ortin. 1992. Chromatin structure of the yeast SUC2 promoter in regulatory mutants. Mol. \& Gen. Genet. 231: 395-400.

Megee, P.C., B.A. Morgan, and M.M. Smith. 1995. Histone H4 and the maintenance of genome integrity. Genes \& Dev. 9: 1716-1727.

Morgan, B.A, B.A. Mittman, and M.M. Smith. 1991. The highly conserved $\mathrm{N}$-terminal domains of histones $\mathrm{H} 3$ and $\mathrm{H} 4$ are 
required for normal cell cycle progression. Mol. Cell. Biol. 11: $4111-4120$.

Mukai, Y., S. Harashima, and Y. Oshima. 1991. AAR1/TUP1 protein, with a structure similar to that of the $\beta$ subunit of $G$ proteins, is required for al- $\alpha 2$ and $\alpha 2$ repression in cell type control of Saccharomyces cerevisiae. Mol. Cell. Biol. 11: 3773-3779.

Orlando, V. and R. Paro. 1995. Chromatin multiprotein complexes involved in the maintenance of transcription patterns. Curr. Opin. Gen. Dev. 5: 174-179.

Rose, M.D., F. Winston, and P. Hieter. 1990. Methods in yeast genetics: A laboratory manual. Cold Spring Harbor Laboratory Press, Cold Spring Harbor, NY.

Roth, S.Y. 1995. Chromatin-mediated transcriptonal repression in yeast. Curr. Opin. Gen. Dev. 5: 168-173.

Roth, S.Y. and R.T. Simpson. 1992. Yeast minichromosomes. Methods Cell Biol. 35: 289-314.

Roth, S.Y., A. Dean, and R.T. Simpson. 1990. Yeast $\alpha 2$ repressor positions nucleosomes in TRP1/ARS1 chromatin. Mol. Cell. Biol. 10: 2247-2260.

Roth, S.Y., M. Shimizu, L. Johnson, M. Grunstein, and R.T. Simpson. 1992. Stable nucleosome positioning and complete repression by the yeast $\alpha 2$ repressor are disrupted by aminoterminal mutations in histone H4. Genes \& Dev. 6: 411425 .

Sambrook, J., E.F. Fritsch, and T. Maniatis. 1989. Molecular cloning: A laboratory manual, 2nd ed. Cold Spring Harbor Laboratory Press, Cold Spring Harbor, NY.

Sathe, S.S. and P.J. Harte. 1995. The Drosophila extra sex combs protein contains WD motifs essential for its function as a repressor of homeotic genes. Mech. Dev. (in press).

Schultz, J. and M. Carlson. 1987. Molecular analysis of SSN6, a gene functionally related to SNF1 kinase of Saccharomyces cerevisiae. Mol. Cell. Biol. 7: 3637-3645.

Schultz, I., L. Marshall-Carlson, and M. Carlson. 1990. The N terminal TPR region is the functional domain of SSN6, a nuclear phosphoprotein of Saccharomyces cerevisiae. Mol. Cell. Biol. 10: 4744-4756.

Shimizu, M., S.Y. Roth, C. Szent-Gyorgyi, and R.T. Simpson. 1991. Nucleosomes are positioned with base pair precision adjacent to the $\alpha 2$ operator in Saccharomyces cerevisiae. EMBO I. 10: 3033-3041.

Simpson, R.T., S.Y. Roth, R.H. Morse, H.G. Patterton, J.P. Cooper, M. Murphy, M.P. Kladde, and M. Shimizu. 1993. Nucleosome positioning and transcription. Cold Spring Harbor Symp. Quant. Biol. 58: 237-245.

Smith, R.L., M.J. Redd, and A.D. Johnson. 1995. The tetratricopeptide repeats of Ssn6 interact with the homeo domain of $\alpha 2$. Genes \& Dev. 9: 2903-2910.

Thompson, J.S., X. Ling, and M. Grunstein. 1994. Histone H3 amino terminus is required for telomeric and silent mating locus repression in yeast. Nature 369: 245-247.

Treitel, M.A. and M. Carlson. 1995. Repression by Ssn6-Tupl is directed by MIGl, a repressor /activator protein. Proc. Natl. Acad. Sci. 92: 3132-3136.

Trumbly, R.J. 1986. Isolation of Saccharomyces cerevisiae mutants constitutive for invertase synthesis. I. Bacteriol. 166: 1123-1127.

Turner, B.M. 1991. Histone acetylation and control of gene expression. J. Cell Sci. 99: 13-20.

Turner, B.M., L. Franchi, and H. Wallace. 1990. Islands of acetylated histone in polytene chromosomes and their relationship to chromatin packaging and transcriptional activity. $J$. Cell Sci. 96: 335-346.

Turner, B.M., A.J. Birley, and J. Lavender. 1992. Histone H4 isoforms acetylated at specific lysine residues define individ- ual chromosomes and chromatin domains in Drosophila polytene nuclei. Cell 69: 375-384.

Tzamarias, D. and K. Struhl. 1994. Functional dissection of the yeast Cyc8-Tupl transcriptional co-repressor complex. $\mathrm{Na}$ ture 369: 758-761.

- 1995. Distinct TPR motifs of cyc8 are involved in recruiting the Cyc8-Tupl corepressor complex to differentially regulated promoters. Genes \& Dev. 9: 821-831.

Van der Lugt, N.M.T., J. Domen, K. Linders, M. Van Roon, E. Robanus-Maandag, H. Te Riele, M. Van der Valk, J. Deschamps, M. Sofroniew, M. Van Lohuizen, and A. Berns. 1994. Posterior transformation, neurological abnormalities, and severe hematopoetic defects in mice with a targeted deletion of the bmi-1 proto-oncogene. Genes \& Dev. 8: 757769.

Wahi, M. and A.D. Johnson. 1995. Identification of genes required for $\alpha 2$ repression in Saccharomyces cerevisiae. Genetics 140: 79-90.

Williams, F.E. and R.J. Trumbly. 1990. Characterization of TUPl, a mediator of glucose repression in Saccharomyces cerevisiae. Mol. Cell. Biol. 10: 6500-6511.

Williams, F.E., U. Varanasi, and R.J. Trumbly. 1991. The CYC8 and TUPl proteins involved in glucose repression in Saccharomyces cerevisiae are associated in a protein complex. Mol. Cell. Biol. 11: 3307-3316.

Zhang, L. and L. Guarente. 1994. Evidence that Tupl/Ssn 6 has a positive effect on the activity of the yeast activator HAPl. Genetics 136: 813-817.

Zhou, Z. and S.J. Elledge. 1992. Isolation of crt mutants constitutive for transcription of the DNA damage inducible gene RNR3 in Saccharomyces cerevisiae. Genetics 131: 851-866.

Zitomer, R.S. and C.V. Lowry. 1992. Regulation of gene expression by oxygen in Saccharomyces cerevisiae. Microbiol. Rev. 56: 1-11. 


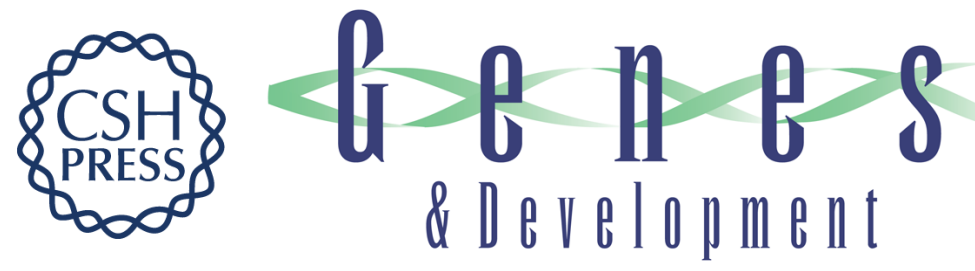

\section{Repression domain of the yeast global repressor Tup1 interacts directly with histones $\mathrm{H} 3$ and $\mathrm{H} 4$.}

D G Edmondson, M M Smith and S Y Roth

Genes Dev. 1996, 10:

Access the most recent version at doi:10.1101/gad.10.10.1247

References This article cites 55 articles, 31 of which can be accessed free at:

http://genesdev.cshlp.org/content/10/10/1247.full.html\#ref-list-1

License

Email Alerting

Service

Receive free email alerts when new articles cite this article - sign up in the box at the top right corner of the article or click here.

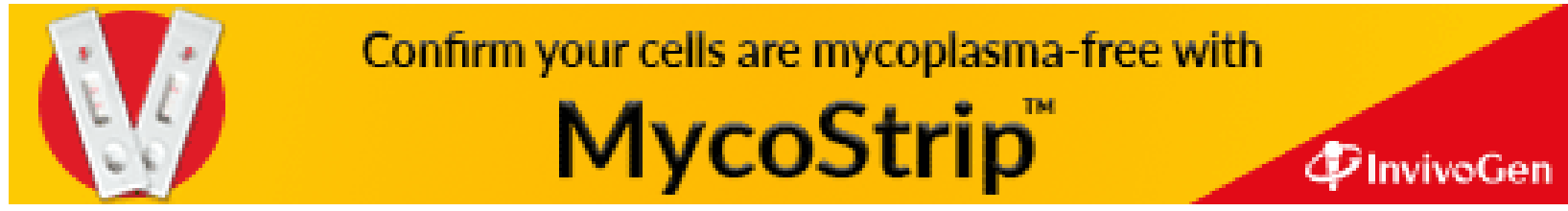

